\title{
Effect of fabrication processes on mechanical properties of glass fiber reinforced polymer composites for 49 meter (160 foot) recreational yachts
}

\author{
Dave (Dae-Wook) Kim, Daniel John Hennigan and Kevin Daniel Beavers
}

Mechanical Engineering, School of Mechanical Engineering and Computer Science, Washington State University Vancouver

\begin{abstract}
Polymer composite materials offer high strength and stiffness to weight ratio, corrosion resistance, and total life cost reductions that appeal to the marine industry. The advantages of composite construction have led to their incorporation in U.S. yacht hull structures over 46 meters (150 feet) in length. In order to construct even larger hull structures, higher quality composites with lower cost production techniques need to be developed. In this study, the effect of composite hull fabrication processes on mechanical properties of glass fiber reinforced plastic (GFRP) composites is presented. Fabrication techniques investigated during this study are hand lay-up (HL), vacuum infusion (VI), and hybrid (HL+VI) processes. Mechanical property testing includes: tensile, compressive, and ignition loss sample analysis. Results demonstrate that the vacuum pressure implemented during composite fabrication has an effect on mechanical properties. The VI processed GFRP yields improved mechanical properties in tension/compression strengths and tensile modulus. The hybrid GFRP composites, however, failed in a sequential manor, due to dissimilar failure modes in the HL and VI processed sides. Fractography analysis was conducted to validate the mechanical property testing results.
\end{abstract}

KEY WORDS: Recreational yacht; Hull structures; Glass fiber reinforced plastics (GFRP); Hand layup; Vacuum infusion; Hybrid composites; Mechanical properties; Failure mechanisms; Composites.

\section{INTRODUCTION}

Fiber reinforced plastic (FRP) materials offer high strength-to-weight and stiffness-to-weight ratios, corrosion resistance, and total life cost reductions which are appealing to the marine industry. The integration of GFRP in maritime use can be seen as far back as the Second World War when small personnel boats for the US Navy were first created with composite material (Mouritz et al., 2001). Immediate popularity grew when it was determined that composites were stiff, strong, durable, easy to repair, and simple to form. Since then, increasing efforts have been made to incorporate these materials into the design of various components and structures for recreational, commercial, and military craft. With current composite technology and manufacturing methods it is possible to manufacture faster, larger, and more fuel efficient vessels, which has become a clear trend in shipbuilding (Capello and Manusco, 2001; Baley, et al., 2006; Borsellino et al., 2007). With increased research efforts, it is possible to incorporate new aged materials such as high strength GFRP, carbon fiber reinforced plastics, and advanced matrix materials into larger recreational yacht hull structures, which are in the $49 \mathrm{~m}$ (160ft) plus range.

Corresponding author: Dave(Dae-Wook) Kim

e-mail:kimd@vancouver.wsu.edu
The most popular composite system for larger yacht hulls is glass fiber reinforced plastics (GFRP), which consist of Eglass fiber reinforcements in a thermoset matrix such as polyester or vinyl ester (Mouring, 1999; Horsmon, 2001). The use of GFRP for larger recreational yachts has been limited due to the high cost of hull construction. A conventional hand lay-up process, which is an open mold process where successive plies of reinforcing materials and resin are applied to the mold by hand, is suitable to small boats (Belingardi et al., 2008). However, it is not cost effective for larger vessels due to its labor-intensive nature (Mouring, 1999). Fabrication of larger recreational yacht hull structures is a cost intensive and high risk technique which must be carefully controlled in order to meet demanding design specifications. As a result the yacht manufacturing industry is interested in investigating longevity, reliability, and cost saving methods involving GFRP materials. When new low cost or high output composite hull fabrication techniques are developed, the mechanical properties should be examined to validate the manufacturing process.

In order to qualify the mechanical properties of hull structural materials, all US yacht manufacturers should follow the "Guide for building and classing motor pleasure yachts" provided by the American Bureau of Shipping (ABS, 2000). According to the ABS Guide, three material tests are required for composite hull construction; tension test (ASTM 
D3039), compression test (ASTM D695) and ignition loss test (ASTM D2584).

In this study, the mechanical properties of GFRP composites manufactured from various composite fabrication techniques were examined. The ABS required material tests for tension, compression and ignition loss, were conducted. Fabrication techniques employed are hand lay-up (HL), vacuum infusion (VI), and hybrid $(\mathrm{HL}+\mathrm{VI})$ processes. The VI process utilizes a vacuum bag to compact a complete laminate ply schedule of reinforcements laid onto the mold. After compaction the resin is infused by the vacuum to completely wet out the reinforcements and eliminate all air voids in the laminate structure (Modi et al., 2007). An investigation into the effects of vacuum pressure during the composite fabrication processes was then performed. This examination is necessary in order to determine the material property changes induced by increased vacuum pressure during fabrication. The VI process is suited for fabrication of inner hull structures which require high strength and thin cross sections. Unlike the inner hull structures, the hybrid composites were chosen for the outer hull structures, where a combined hand layup and vacuum infusion technique was used. Here the hybrid term refers to composite material formed by applying the HL technique to construct the exterior layup against the mold, followed by a VI process on the interior once the HL portion is cured. This form of hybrid composite assembly is advantageous for both composite structural performance and ease of manufacturing. From the structural point of view, the outer hull exterior skins should possess a good resistance to wave impact or local shock loads (Belingardi et al., 2008) while the interior skin provides high strength and stiffness. From the manufacturing point of view, the outer hull exterior skins require detailed work particularly in the corners and the gaps between molds. The HL process is suitable as an initial layup, because it prevents any defects, which could cause leakage during the VI process. These defects include resin leaking at the mold gap or large void formation at the mold/vacuum bag interface. The hybrid GFRP system is a particularly interesting layup and mechanical property testing should yield new results, which will aid in further process development. The material properties and failure mechanisms which form due to this particular layup will help to shed light on the effects and advantages of hand layup and vacuum infusion techniques.

\section{EXPERIMENTAL PROCEDURE}

\section{Material Systems and Their Fabrication Techniques}

Fig. 1 (a) shows a typical recreational yacht hull structure, which consists of four laminates at outer hull side, inner hull side, outer hull bottom and outer hull side. A table in Fig. 1 is a reference to the different sample names along with fabrication process, vacuum pressure during the process, and component position on the vessel. Four samples (VH-6, VH12, HYB-18, and HYB-19) were fabricated for the hull structure while two samples (HL-6 and VL-6) were prepared for experimental use only. The sample names are related to the fabrication process and the number of plies used to fabricate each sample. For all matrix materials the catalyst is $2 \mathrm{wt} \%$ methyl ethyl ketone peroxide.

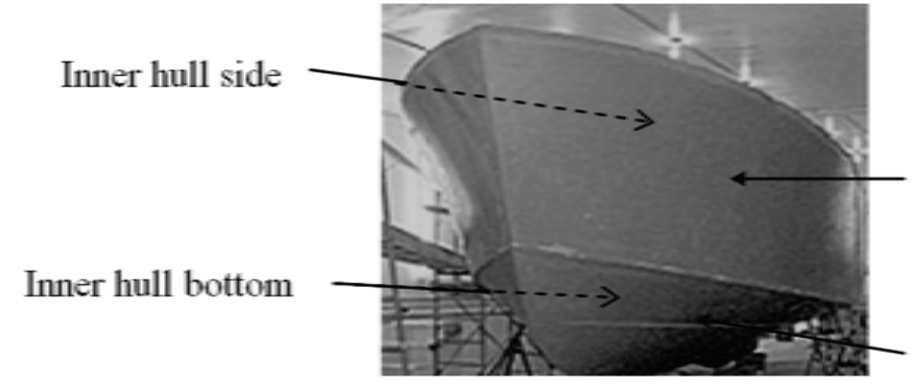

(a) Hull structure example.

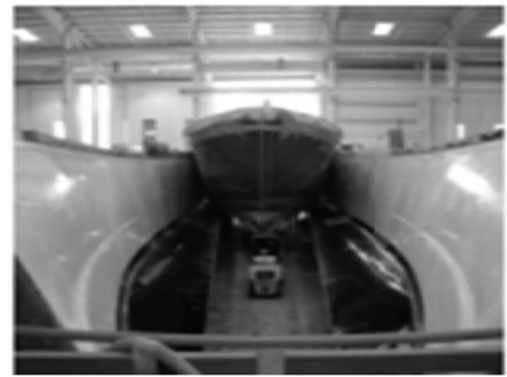

(b) Hull extracted from molds.

(c) Composite samples used for the study.

\begin{tabular}{|c|c|c|c|}
\hline $\begin{array}{c}\text { Sample } \\
\text { Name }\end{array}$ & Fabrication Process Description & $\begin{array}{c}\text { Process Pressure } \\
\text { (inch } \mathrm{Hg})\end{array}$ & Hull Positions \\
\hline HL-6 & Hand layup process & 0 & Experimental Use Only \\
\hline VL-6 & Vacuum infusion process with medium pressure & 20 & Experimental Use Only \\
\hline VH-6 & Vacuum infusion process with high pressure & 28 & Inner Hull Side \\
\hline VH-12 & Vacuum infusion process with high pressure & 28 & Inner Hull Bottom \\
\hline HYB-18 & $\begin{array}{c}\text { Hybrid composite (Hand layup + Vacuum infusion } \\
\text { process with high pressure) }\end{array}$ & 0 and 28 & Outer Hull Side \\
\hline HYB-19 & $\begin{array}{c}\text { Hybrid composite (Hand layup + Vacuum infusion } \\
\text { process with high pressure) }\end{array}$ & 0 and 28 & Outer Hull Bottom \\
\hline
\end{tabular}

Fig. 1 (a) Hull structure example, (b) hull extracted from moulds, and (c) the composite samples used for the study. 
The conventional HL process was used to consolidate the HL-6 sample. Glass fibers were placed manually inside of a mold then matrix material was spread evenly over the fiber layers. Entrapped air was then removed with squeegees and rollers. Hardening of the fiber/matrix system was accomplished at ambient temperature. In order to complete the VI process fibers were placed into or on top of a mold. The fibers were then coated in matrix and the entire layup was covered in plastic. Vacuum was then applied in order to spread the matrix throughout the fiber evenly. Preliminary testing showed that the vacuum pressure should be at least 20 " $\mathrm{Hg}$ in order to gain the largest benefit in void reduction. The VL-6 sample was processed at $20^{\prime \prime} H g$, while VH-6 and VH12 samples were processed at the vacuum facility limit of 28 " $H g$. The VI processed samples created using the high pressure set up were used for the inner hull structures.

Hybrid composite laminates (HYB-18 and HYB-19 samples) were used for the outer hull side and outer hull bottom. The hybrid composite samples were formed by first using the HL technique to place three to four plies of mat material, along with 1 set of Owens Corning CDM 2408 which has an $[\mathrm{M} / 90 / 0]$ layup of fibers. This laminate is allowed to fully cure, then a VI process is completed at $28^{\prime \prime}$ $\mathrm{Hg}$ on the inside consisting of four sets of Vectorply E-LTM 3612 . Once this assembly dries there are unique properties of both laminate types found in the hybrid composite material.

Table 1 gives a detailed description of the six material systems investigated over the course of this experiment. It is composed of 6 columns which help to define the 6 composite laminates in an easy to understand format. The first column introduces the sample name. The orientation column fully describes the laminate layup sequence, which for the most part is a mat, 90 degree, 0 degree method with variance mainly in the number of ply sets used. E-glass materials from Vectorply E-LTM 3610, 3611, and 3612 were utilized for the VI processed laminates. For the HL side of the hybrid laminates, another type of E-glass (Owens Corning CDM 2408) was used. Two matrix materials were utilized during testing which include Derakane Momentum 411-200 epoxy vinyl ester for the VI processed laminates, and Reichhold Hydrex 100 epoxy vinyl ester for the HL side of the hybrid samples. The last column shows the total thickness of the composite samples after fabrication processes were complete.

Table 1 Material systems used in this study.

\begin{tabular}{|c|c|c|c|c|c|}
\hline $\begin{array}{l}\text { Sample } \\
\text { Name }\end{array}$ & $\begin{array}{l}\text { No of } \\
\text { Plies }\end{array}$ & Orientation & Glass Material & $\begin{array}{l}\text { Matrix } \\
\text { material }\end{array}$ & $\begin{array}{l}\text { Thickness } \\
\qquad(\mathrm{mm})\end{array}$ \\
\hline HL-6 & 6 & {$[\mathrm{M} / 90 / 0]_{2}$} & Vectorply E-LTM 3610 & A & 3.66 \\
\hline VL-6 & 6 & {$[\mathrm{M} / 90 / 0]_{2}$} & Vectorply E-LTM 3610 & A & 2.46 \\
\hline VH-6 & 6 & {$[\mathrm{M} / 90 / 0]_{2}$} & Vectorply E-LTM 3612 & $\mathrm{~A}$ & 2.39 \\
\hline VH-12 & 12 & {$[\mathrm{M} / 90 / 0]_{4}$} & Vectorply E-LTM 3611 & A & 5.08 \\
\hline \multirow{2}{*}{ HYB-18 } & \multirow{2}{*}{18} & \multirow{2}{*}[\mathrm{M}_{3\mathrm{H}}/(\mathrm{M}/90/0)_{1\mathrm{H}}/(\mathrm{M}/90/0)_{4\mathrm{V}}]{} & $\begin{array}{l}\text { Owens Corning CDM } 2408 \text { for the } \\
\text { handlay-up processed plies }\end{array}$ & B & \multirow{2}{*}{7.75} \\
\hline & & & $\begin{array}{l}\text { Vectorply E-LTM } 3612 \text { for the } \\
\text { vacuum infusion processed plies }\end{array}$ & A & \\
\hline \multirow{2}{*}{ HYB-19 } & \multirow{2}{*}{19} & \multirow{2}{*}[\mathrm{M}_{4\mathrm{H}}/(\mathrm{M}/90/0)_{1\mathrm{H}}/(\mathrm{M}/90/0)_{4\mathrm{V}}]{} & $\begin{array}{l}\text { Owens Corning CDM } 2408 \text { for the } \\
\text { handlay-up processed plies }\end{array}$ & B & \multirow{2}{*}{7.80} \\
\hline & & & $\begin{array}{l}\text { Vectorply E-LTM } 3612 \text { for the } \\
\text { vacuum infusion processed plies }\end{array}$ & $\mathrm{A}$ & \\
\hline \multicolumn{6}{|c|}{$\begin{array}{l}M=\text { mat: layer of chopped fibers with approximately } 1 \mathrm{~mm} \text { thickness after curing } \\
A=\text { Derakane Momentum } 411-200 \text { Epoxy Vinyl Ester } \\
B=\text { Reichhold Hydrex } 100 \text { Epoxy Vinyl Ester } \\
H=\text { hand layup process } \\
V=\text { vacuum infusion process }\end{array}$} \\
\hline
\end{tabular}

\section{Mechanical property test procedures}

Static tension and compression tests were conducted to investigate the performance of the six reviewed composite samples. Tensile properties such as tensile modulus, tensile strength, and strain at failure of composite laminates were determined in accordance with ASTM D3039. A universal mechanical tester (Instron Model 4482) and an extensometer 
(Instron 2630-100 series clip on type) were used for the tension test with a cross head speed of $2 \mathrm{~mm} / \mathrm{min}$.

Properties in compression were determined by static compression tests in accordance with ASTM D695. Loading of the specimen was at a standard cross head speed of 1.3 $\mathrm{mm} / \mathrm{min}$. A strain gage was placed in the center of the specimen to measure the strain state during testing. More than five coupons were tested for each sample type in order to achieve accurate average values. Fig. 2 shows the test sample configurations of ASTM D3039 and ASTM D695, respectively.
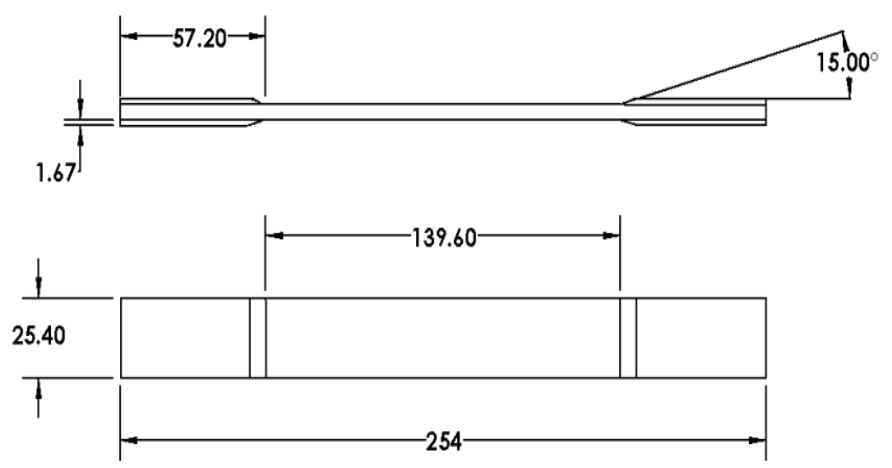

(a) Tension test sample (ASTM D3039).

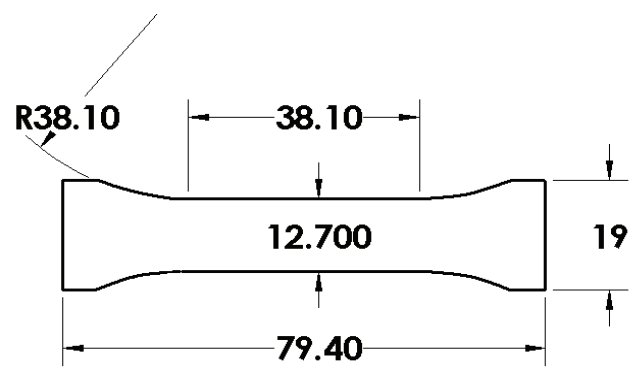

(b) Compression test sample (ASTM D695).

Fig. 2 Test sample configurations in $\mathrm{mm}$.

Ignition loss tests were performed in accordance with ASTM D2584. This type of test is used to measure fiber and resin weight percent, sample density, and percent void content. Testing was carried out in a Lucifer model RD7-H21 furnace at $565^{\circ} \mathrm{C}$ for one hour. Prepared samples were weighed and measured before and after leaving the oven to determine the amount of matrix material burned off, and the remaining weight of the fiber.

\section{RESULTS AND DISCUSSION}

\section{Effects of vacuum pressure}

\section{Void content}

Ignition loss tests were used to verify the effects of vacuum pressure on each of the material systems investigated.
Three different pressures were analyzed: $0^{\prime \prime}, 20^{\prime \prime}$, and $28^{\prime \prime} H g$, during the fabrication of the samples seen in Table 2 . Specimens were also created with vacuum pressures set at $5^{\prime \prime}$ and $10^{\prime \prime} \mathrm{Hg}$, but their void content was not very different from hand layup, and so they were not included here. The vacuum infusion facility's maximum capacity was $28^{\prime \prime} \mathrm{Hg}$, which was only limited by the vacuum pump itself.

Table 2 Average fiber vs. matrix wt $\%$, vol $\%$, and sample density.

\begin{tabular}{|c|c|c|c|c|}
\hline \multicolumn{2}{|c|}{ Property / Samples } & HL-6 & VL-6 & VH-6 \\
\hline \multicolumn{2}{|c|}{ Density $(g / c c)$} & 1.53 & 1.76 & 1.81 \\
\hline \multirow{2}{*}{$\begin{array}{c}\text { Weight } \\
\%\end{array}$} & Fiber & 53.7 & 68.9 & 70.7 \\
\cline { 2 - 5 } & Matrix & 46.3 & 31.1 & 29.3 \\
\hline \multirow{2}{*}{$\begin{array}{c}\text { Volume } \\
\%\end{array}$} & Fiber & 31.9 & 47.7 & 49.9 \\
\cline { 2 - 5 } & Matrix & 66.0 & 50.8 & 49.5 \\
\cline { 2 - 5 } & Void & 2.1 & 1.5 & 0.6 \\
\hline
\end{tabular}

Table 2 shows the ignition test results for the three evaluated material systems: HL-6, VL-6, and VH-6. By increasing pressure from ambient to $28^{\prime \prime} \mathrm{Hg}$ a $71 \%$ decrease in void volume was realized. This reduction in voids leads to a $36 \%$ increase in fiber weight percent per unit volume. Overall the decreased void content leads to a more intimate matrix fiber interface with fewer stress concentrations and loose fibers. Another benefit of high vacuum pressure is the decrease in matrix needed to fully saturate the fiber. This saves valuable resources and allows for a better understanding of the exact quantity of matrix material necessary to complete a project (Borsellino et al., 2007). As vacuum increases the fiber is also compacted neatly, which aids in load distribution and offers a thinner cross section with a higher amount of strength per unit volume.

\section{Tensile properties}

Changes in vacuum pressure had very profound effects on the tensile properties of the GFRP samples tested. In all, 5 specimens were created from each of the three panel types: HL-6, VL-6 and VH-6 in accordance with ASTM 3039. The vacuum pressure was then varied between $0^{\prime \prime}$ (ambient): 20" $H g: 28^{\prime \prime} H g$ respectively. All of the samples are identical in every regard accept for the vacuum pressure used during fabrication which made it possible to observe the differences in tensile modulus, ultimate tensile strength, and maximum percentage strain at failure. Fig. 3 (a) shows the typical tensile stress-strain curves for HL-6, VL-6, and VH-6 samples. 
From the data in Fig. 3 (a), it is quite apparent that changes in the vacuum pressure lead to drastic changes in the tensile properties of the selected materials. The tensile modulus and strength increase considerably with increasing amounts of vacuum pressure. Ultimate tensile strength (UTS), tensile modulus and maximum percent strain values were averaged across the 5 specimens from each sample type and are found in Table 3 along with the corresponding vacuum pressure. The values in Table 3 lead to the conclusion that a change in vacuum pressure from ambient $\left(0^{\prime \prime} \mathrm{Hg}\right)$ to $28^{\prime \prime} \mathrm{Hg}$ will provide a $248.1 \mathrm{MPa}$ or $147 \%$ increase in the ultimate tensile strength. Tensile modulus is also greatly affected with a $6.39 \mathrm{GPa}$ or $39 \%$ increase between the HL-6 and the VH-6 samples.

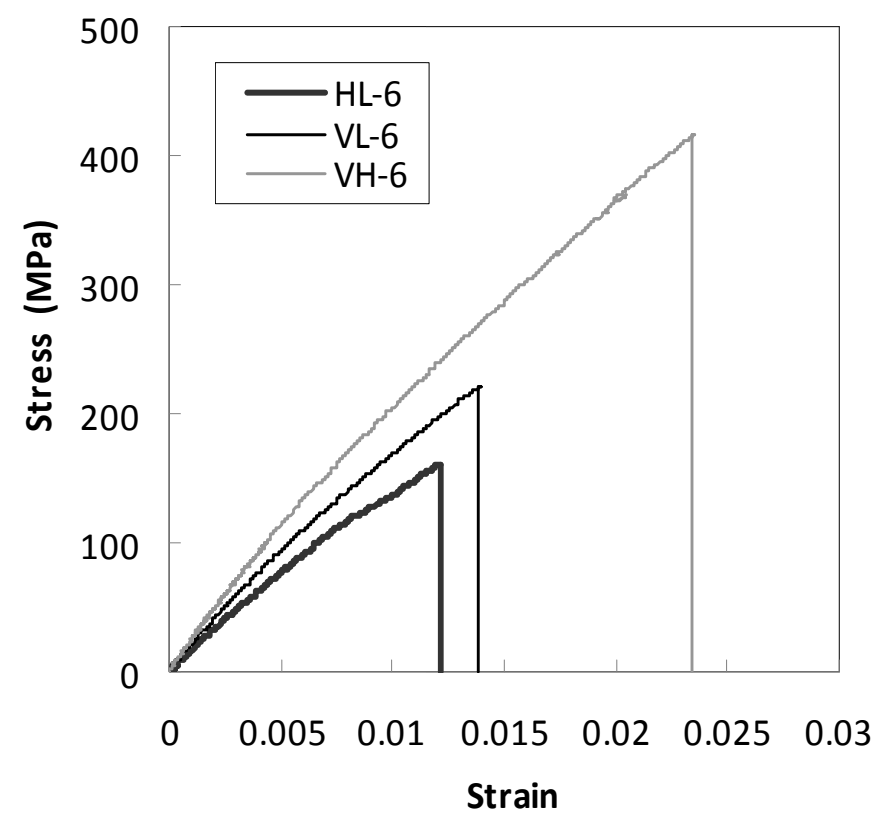

(a) Typical tensile stress vs. strain curves for HL-6, VL-6, and VH-6 samples.

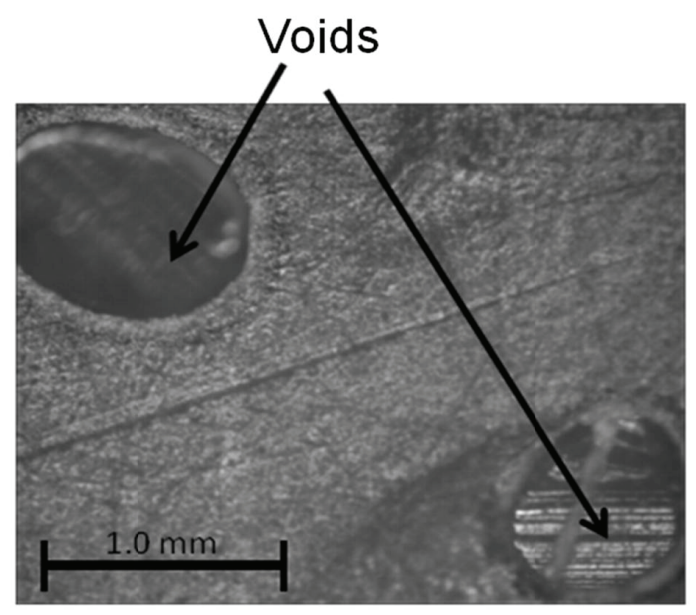

(b) Voids observed in a HL-6 sample.

Fig. 3 Typical tensile stress vs. strain curves for HL-6, VL-6, and VH-6 samples, and voids observed in a HL-6 sample.
In order to explain the test results it is first necessary to understand the mechanisms of failure in composite materials. Voids, for example, are known to accelerate failure due to a weakening of the interface between the fiber and the matrix. These weak points lead to stress concentrations which cause de-bonding of fiber, fiber shearing, and premature matrix cracking when tensile forces are applied to the structure (Thomason, 1995; Costa et al., 2001). Fiber de-bonding and pullout mainly occur when the matrix material is not fully saturated around the fiber structure (Mallick, 2007). As shown in Fig. 3 (b), voids were observed in the hand lay-up processed HL-6 samples. Some voids were even visible and as large as a few millimeters.

Table 3 Average Tensile Properties with varied vacuum pressure.

\begin{tabular}{|c|c|c|c|c|}
\hline & HL-6 & VL-6 & VH-6 & VH-12 \\
\hline $\begin{array}{c}\text { Vacuum pressure } \\
(H g)\end{array}$ & 0 & 20 & 28 & 28 \\
\hline $\begin{array}{c}\text { UTS } \\
(M P a)\end{array}$ & 168.7 & 218.6 & 416.8 & 416.07 \\
\hline $\begin{array}{c}\text { Modulus } \\
(G P a)\end{array}$ & 16.03 & 19.89 & 22.42 & 22.81 \\
\hline \begin{tabular}{c} 
Max \% Strain \\
\hline
\end{tabular} & 1.279 & 1.310 & 2.363 & 2.51 \\
\hline
\end{tabular}

These voids lead to early failure of the voided regions, and eventually to overall failure of the composite at lower levels than to be expected. Fig. 4 shows fracture surface of an HL-6 sample, where premature matrix cracking caused by voids is dominant. Here the pockets where voids lie crack and follow the path of least resistance to the next void in the structure. Eventually a crack forms which moves from void to void through the matrix material, and finally culminates in matrix failure, fiber failure, and ultimate failure of the composite. Unlike the hand lay-up processed samples, the vacuum infusion processed sample with 28" $H g$ (VH-6 samples) appears ruptured, with fibers being extracted deep within the matrix. Higher interfacial bonding between fiber and matrix will improve the ability of a composite material to undergo loading (Costa, 2001). On the SEM picture with higher magnification, matrix material still clings to individual strands of fibers of the VH-6 sample even after failure, which suggests that the interfacial shear strength between fiber and matrix is exceptionally high. As shown in the SEM picture with high magnification, the opposite is seen with the HL-6 specimen. Here there is relatively no matrix material left behind indicating lower interfacial strength between fiber and matrix. When there is lower interfacial strength, a broken fiber will simply slip away from the surrounding matrix. The fracture patterns of the VL-6 samples are close to those of the HL-6 samples, however they show moderate fiber extractions which are common in the VH-6 samples. 


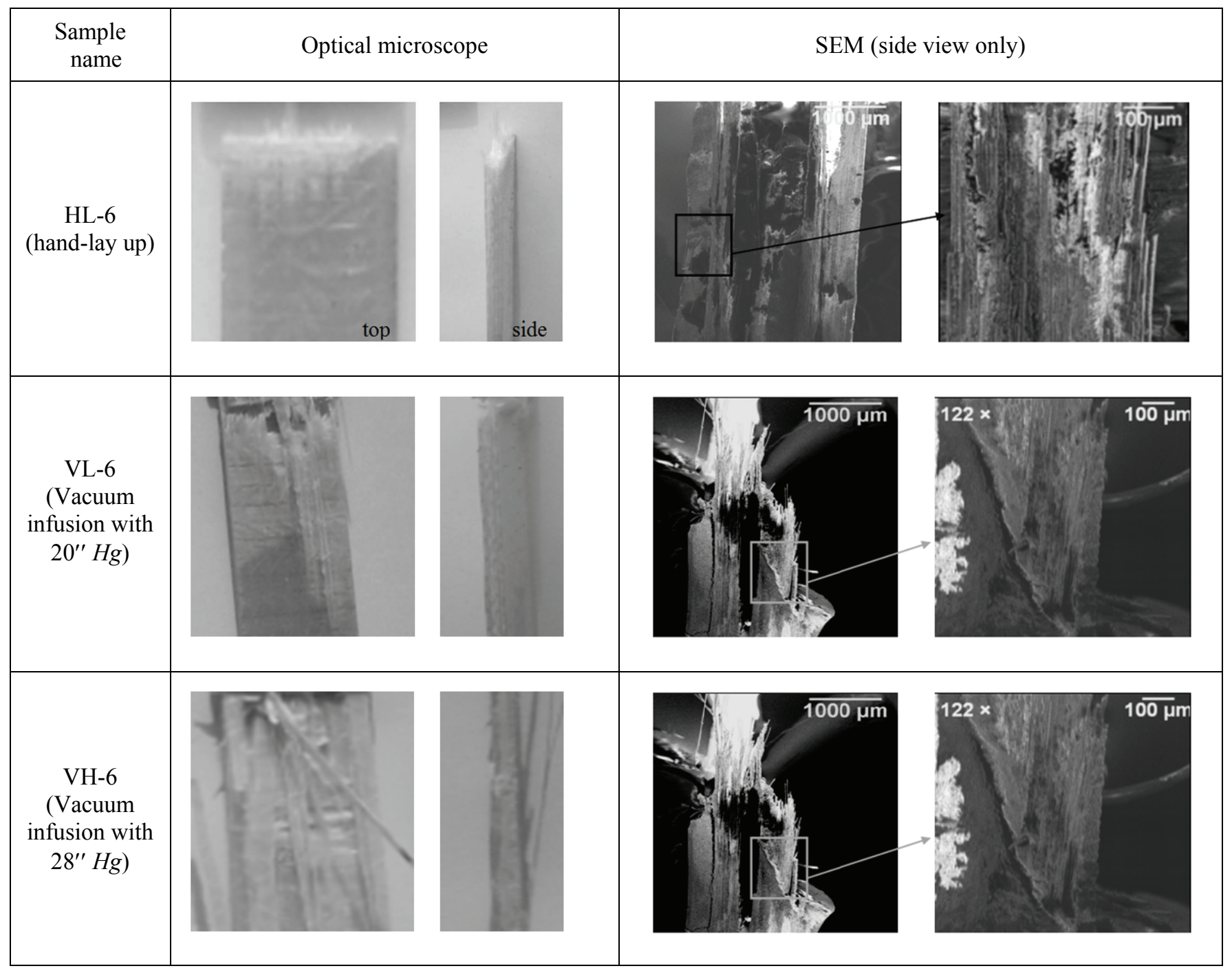

Fig. 4 Fractography of HL-6, VL-6, and VH-6 samples.

\section{Compressive Properties}

Compression testing was conducted to understand the effects of variance in vacuum pressure on the compressive properties of the GFRP samples. Again, 5 specimens were fabricated from each of the three panel types: HL-6, VL-6 and VH-6 in accordance with ASTM D695. Fig. 5 shows the typical compressive stress-strain curves for the samples. Averages of each property for each 5 specimen batch are located in Table 4. Table 4 also includes the compression test results of the VH-12 sample to verify the effect of sample thickness on compressive properties.

The data collected in Fig. 5 and Table 4 shows some very interesting trends, some of which were unanticipated. An overall increase in compressive modulus was found, as expected, but the ultimate compressive strength (UCS) slightly declined as the vacuum pressure was increased. The decreasing trend for UCS can be well explained with the maximum percent strain, and the failure mode. These thin six ply composite samples demonstrated end failures that are often referred to as 'brushing' or 'end crushing'.

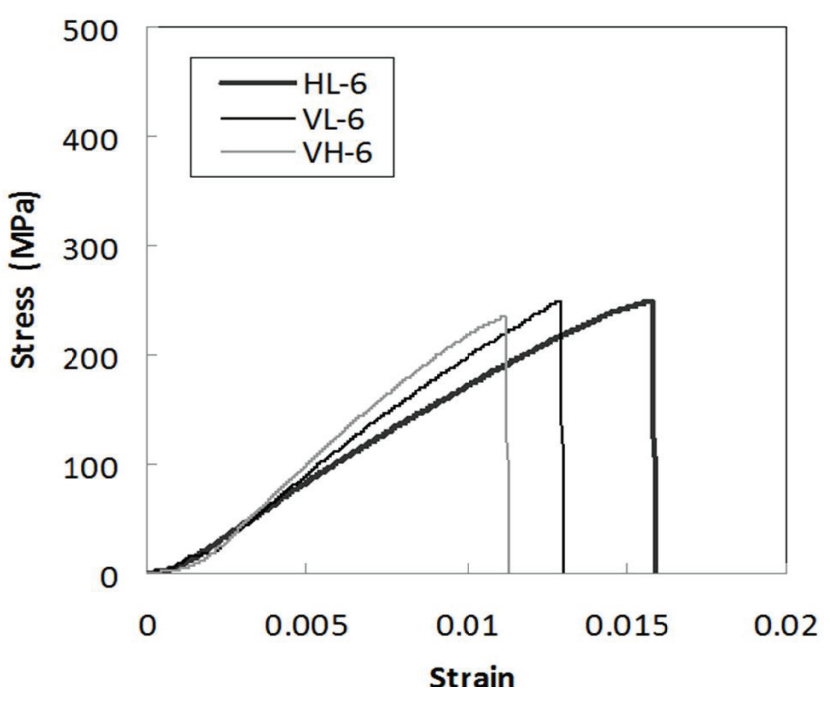

Fig. 5 Typical compressive stress vs. strain curves for HL-6, VL-6, and VH-6 samples. 
As shown in Fig. 6, end crushing was found to be the dominant failure mode for most samples with 6 plies and vacuum infusion processing. It should be noted that the vacuum infusion processed samples are $48 \%$ to $53 \%$ thinner than the hand layup processed samples.

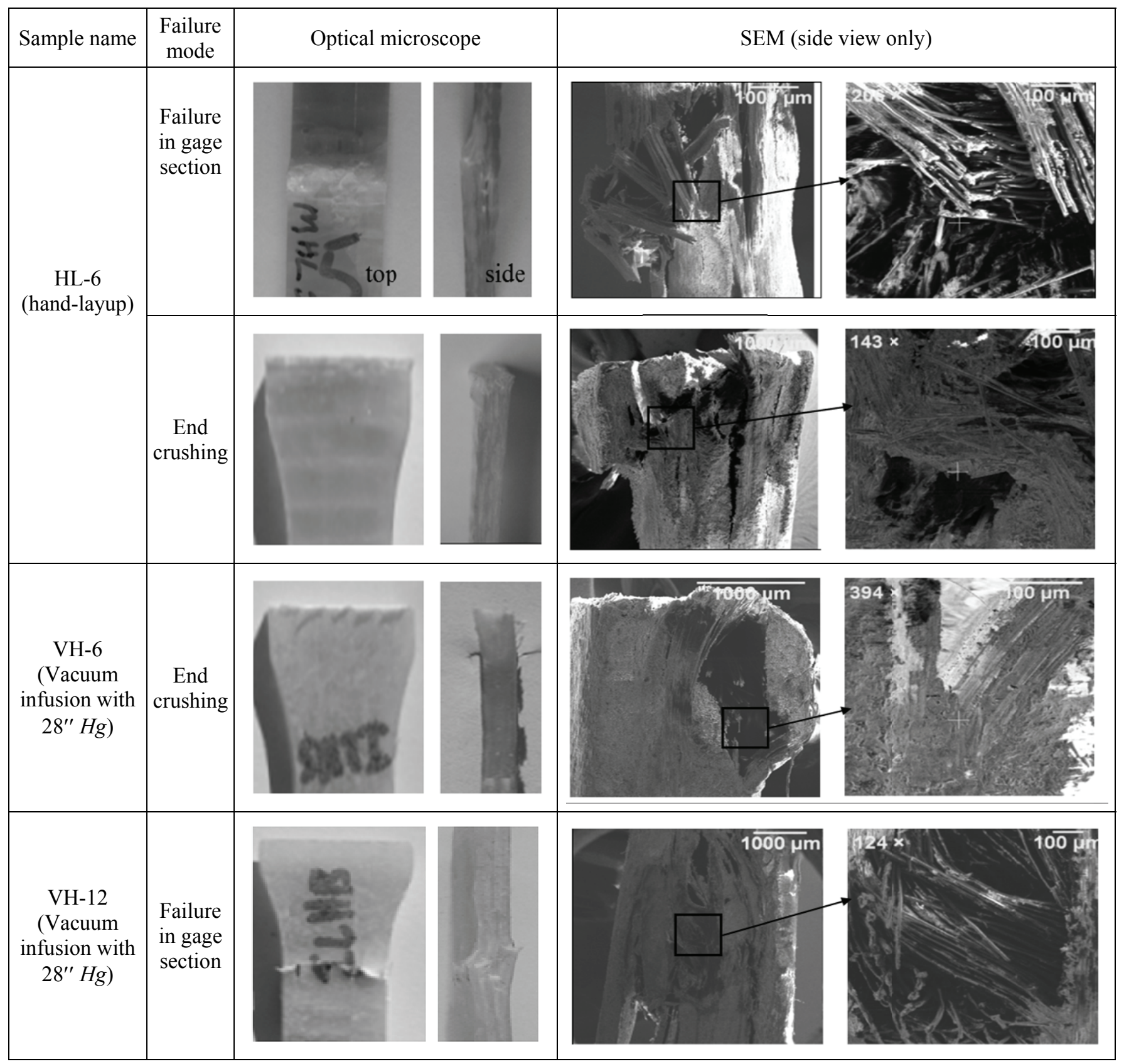

Fig. 6 Fractography of HL-6, VH-6, and VH-12 samples.

For pure compression loading, transverse stresses are induced at the ends of the specimen due to Poisson deformation. This type of load can easily cause end crushing of the specimen (Squires et al 2007, Adams and Lewis 1991). End crushing is a premature failure mode, and here it can be seen that the brushing effect causes the composites to fail at a lower \% strain. This means failure in the VH-6 samples happened earlier than the HL-6 sample. It can be determined from the data that as the layers of fiber increase the compressive strength increases and premature failure modes such as end crushing were not observed. Table 4 shows compressive properties of the $\mathrm{VH}-12$ sample, which is approximately $106 \%$ thicker than the VH- 6 samples. An average strength increase of $105.2 \mathrm{MPa}$ or $47 \%$ in the $\mathrm{VH}-12$ samples was experienced when compared with the VH-6 samples. As shown in Fig. 6, failure within the gage region is most likely to be seen in the VH-12 sample from modes such as fiber kinking, longitudinal splitting, shear crippling, or micro-buckling where matrix and fibers both fracture nearly simultaneously (Mallick, 2007; Schultheisz and Wass, 1996). 
Therefore, end crushing or premature failure of the VH- 6 samples result in a lower average UCS value than expected and yield no noticeable difference in UCS when compared with the HL-6 sample.

Table 4 Average Compressive Properties of selected materials.

\begin{tabular}{|c|c|c|c|c|}
\hline & HL-6 & VL-6 & VH-6 & VH-12 \\
\hline $\begin{array}{c}\text { Vacuum pressure } \\
(" \mathrm{Hg})\end{array}$ & 0 & 20 & 28 & 28 \\
\hline $\begin{array}{c}\text { Sample thickness } \\
(\mathrm{mm})\end{array}$ & 3.66 & 2.46 & 2.39 & 5.08 \\
\hline $\begin{array}{c}\text { Ultimate compressive } \\
\text { strength }(\mathrm{MPa})\end{array}$ & 237.62 & 223.46 & 221.23 & 326.41 \\
\hline $\begin{array}{c}\text { Modulus } \\
(\mathrm{GPa})\end{array}$ & 18.03 & 21.62 & 25.81 & 24.04 \\
\hline $\begin{array}{c}\text { Max \% Strain } \\
\text { Typical failure } \\
\text { modes }\end{array}$ & $\begin{array}{c}1.503 \\
\text { section/ } \\
\text { End } \\
\text { Eage } \\
\text { crushing }\end{array}$ & 1.254 & 1.060 & 1.578 \\
\hline crushing & $\begin{array}{c}\text { End } \\
\text { crushing }\end{array}$ & $\begin{array}{c}\text { Shear in } \\
\text { gage } \\
\text { section }\end{array}$ \\
\hline
\end{tabular}

The beneficial effect of high vacuum pressure in composite fabrication was found in compressive modulus. From Table 4 it is apparent that modulus is increasing with increasing pressure. The total average compressive modulus increase was $7.78 \mathrm{GPa}$ or $43 \%$ between the HL- 6 and the VH-6 samples $\left(0^{\prime \prime}\right.$ and $\left.28^{\prime \prime} \mathrm{Hg}\right)$. Premature failure in end crushing does not have an effect on the modulus so these values give a good idea of what the composite strength should be. In Table 4, modulus is consistent among the samples (VH-6 and VH-12) with various thicknesses and the same fabrication condition.

\section{Mechanical properties of hybrid composites}

\section{Tensile Properties}

Static tension tests were performed on each of the hybrid composite samples, HYB-18 and HYB-19. Fig. 7 (a) shows a typical stress-strain curve for the hybrid composite samples. There are four distinct regions in the curve, which can be compared to the failure evolution schematic seen in Fig. 7 (b). By combining the graph and the schematic it becomes clear that the failure of each particular section of the laminate gives rise to unique characteristics in the stress-strain curve. In region 1, the graph rises steadily and both HL and VI processed sides are stressed equally. The curve hits its first peak and drops a bit at region 2. This is mainly due to the failure in the HL side of the sample. This abrupt failure causes a drop in the amount of load being carried by the composite while strain remains the same. The initial failure in the HL side is expected because the layup sequence of the HL side mostly consists of plies with chopped glass fiber mat.
In addition, the HL processed laminate showed less UTS and max $\%$ strain when compared with the VI processed laminates, as explained earlier. The curve steadily rises again through region 3 where the VI portion of the sample is still intact and continues to carry load. Finally the VI portion of the sample reaches the second and maximum peak followed by the ultimate failure of the material in region 4 .

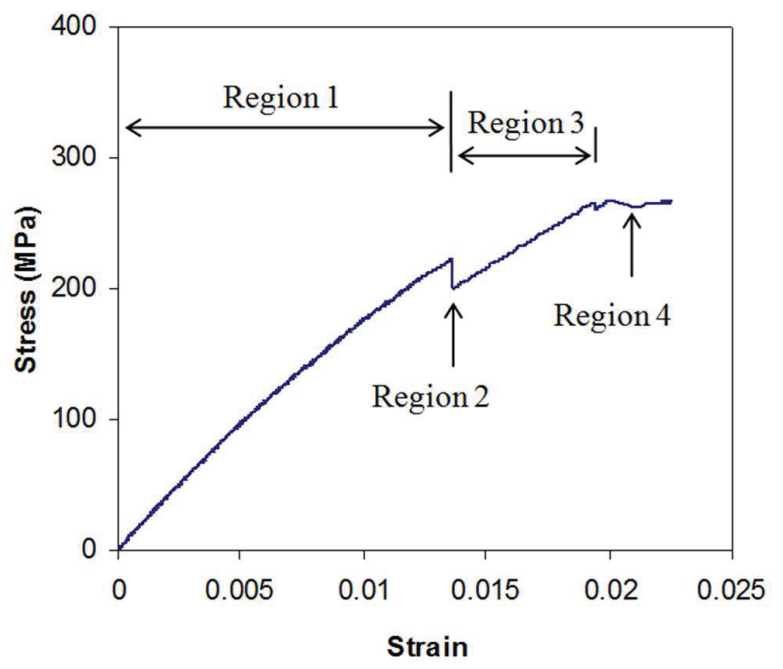

(a) Typical stress vs. strain graph of the hybrid samples (HYB-19 Specimen \#2-T).

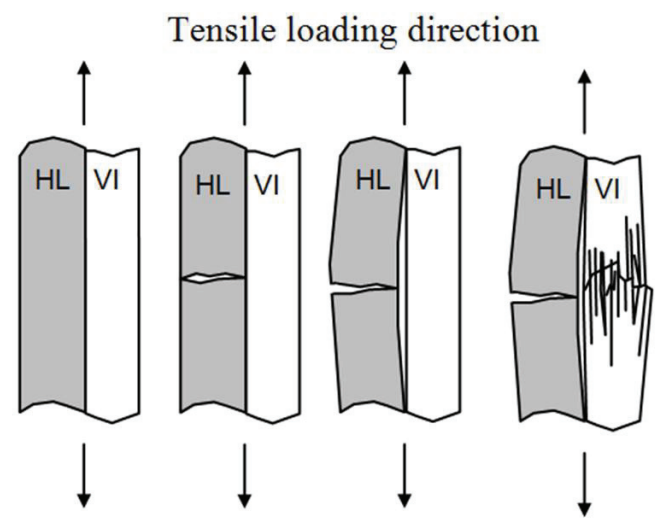

Region 1 Region 2 Region 3 Region 4

(b) Schematics of failure sequences in tension test.

Fig. 7 (a) typical stress vs. strain graph of the hybrid samples (HYB-19 Specimen \#2-T) and (b) the schematics of failure sequences in tension test.

Five specimens were tested and averaged from each sample type. The average property values in each failure region were then input into Table 5 in order to more fully define the material failure characteristics. It was also useful to compare the hybrid composite samples with a VH-12 specimen, which has the same characteristic layup as the VI side of the hybrid layups. 
Table 5 Tensile Properties of HYB- 18 and HYB- 19.

\begin{tabular}{|c|c|c|c|}
\hline \multicolumn{2}{|c|}{ Sample name } & HYB-18 & HYB-19 \\
\hline \multirow{3}{*}{$\begin{array}{c}\text { Material } \\
\text { contents }\end{array}$} & $\begin{array}{c}\text { Resin content } \\
(\text { weight \%) }\end{array}$ & 42.3 & 41.9 \\
\cline { 2 - 4 } & $\begin{array}{c}\text { Fiber content } \\
(\text { weight \%) }\end{array}$ & 57.7 & 58.1 \\
\hline \multirow{4}{*}{$\begin{array}{c}\text { Tensile } \\
\text { test } \\
\text { results }\end{array}$} & $\begin{array}{c}\text { Modulus in region 1 } \\
(\mathrm{GPa})\end{array}$ & 17.87 & 18.55 \\
\cline { 2 - 4 } & $\begin{array}{c}\text { Max strength in region 2 } \\
(\mathrm{MPa})\end{array}$ & 225 & 230 \\
\cline { 2 - 4 } & $\begin{array}{c}\text { Modulus in region 3 } \\
(\mathrm{GPa})\end{array}$ & 10.6 & 11.5 \\
\cline { 2 - 4 } & $\begin{array}{c}\text { UTS or Strength in region 4 } \\
(\mathrm{MPa})\end{array}$ & 269.97 & 278.45 \\
\hline \multicolumn{2}{|c|}{ Max \% strain } & 2.358 & 2.219 \\
\hline
\end{tabular}

Overall the failure of HYB-18 and HYB-19 occurs in much the same fashion although it was found that HYB-19 shows slightly improved properties over HYB-18 in all failure areas. This is actually a little unusual due to the fact that the mat section which adds the extra layer of material fails before the VI portion in all HYB composites (Fig. 7). Since the VI side is the same material and thickness for both hybrid composites, final failure should occur at the same stress state.

The probable cause for deviation in values of VI side failure was narrowed down to the resin content of HYB-18 which is $0.4 \%$ higher than HYB-19. This would lead to lower overall strength and modulus along with a higher maximum percent strain at failure in HYB-18.

Other interesting results were found by looking at each individual failure region on the graph. In region 1, for example, the HYB samples display a much lower modulus (17.87 MPa or $18.55 \mathrm{MPa}$ ) than can be found in the VH-12 samples $(22.81 \mathrm{MPa})$. This is due to the HL side of the hybrid composite which offers lower stiffness by volume due to voids and bilateral (mat) material construction. Region 2 of the failure curve is also much different between the hybrid composite and VH-12 samples. Here the average maximum strength for the hybrid composite samples ranges from 225 to $230 \mathrm{MPa}$. This is much less than the VH-12 sample, but is an improvement on the HL processed sample (HL-6) which was mentioned earlier. The VI side of the hybrid layup adds much needed strength and improves this property above the typical hand layup strength. In region 3 of the failure graph the modulus of the HYB samples ranges from 10.6 to $11.5 \mathrm{GPa}$. This is a little misleading however since the thickness of the sample has been reduced here due to the failure of the HL side of the hybrid sample. Once thickness is accounted for the modulus is raised to $17-18 \mathrm{GPa}$, which is still below the average modulus value (22.81 $\mathrm{MPa}$ ) of the $\mathrm{VH}-12$ samples. It is believed that micro failures in the VI side, occurred prior to region 3 and lead to lower modulus values in the hybrid composites than in the VI composite alone. Finally the average UTS of the hybrid composites are much lower than that (416.07 MPa) of the VH-12 samples. This is due to the failure of the HL side of the hybrid composite and the included change in thickness after failure.

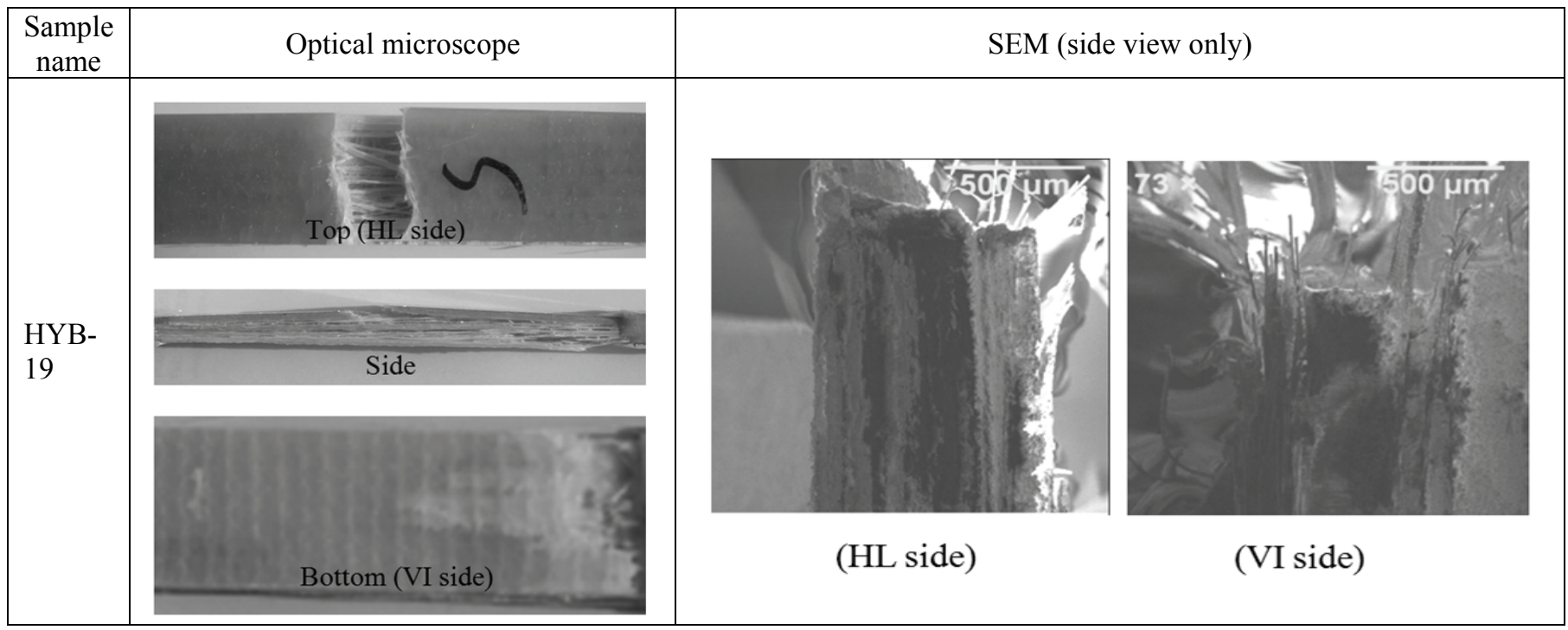

Fig. 8 Fractography of hybrid composite laminate after compression test (HYB-19 Specimen \#5-T).

Fig. 8 shows the overall pictures and the SEM micrographs of the fracture surfaces of a HYB specimen. The differences between two different sides (the HL and VI sides) are obvious. The HL side, which consists of mostly chopped fiber mats, showed a flat fractured surface due to the brittle fracture from the matrix. Most chopped fibers are pulled out from the matrix. Note that fiber pull-out and axial splitting, which are the effective energy dissipation mechanisms, may enhance the impact energy of the laminate, which can be beneficial to wave impact (Fu et al., 2000; Rodriguez et al., 2005). Unlike the HL side, the fibers being extracted deep within the matrix were observed in the VI side. Note that local delamination was observed between the HL and VI sides, however they are not split completely after failure. 
This means both sides adhere well during the formation of the hybrid structure.

\section{Compressive Properties}

Static compression testing was accomplished in accordance with ASTM D695. Fig. 9 (a) and (b) show the typical stress strain curve in compression for the hybrid samples and the failure evolution schematic which coincides with it.

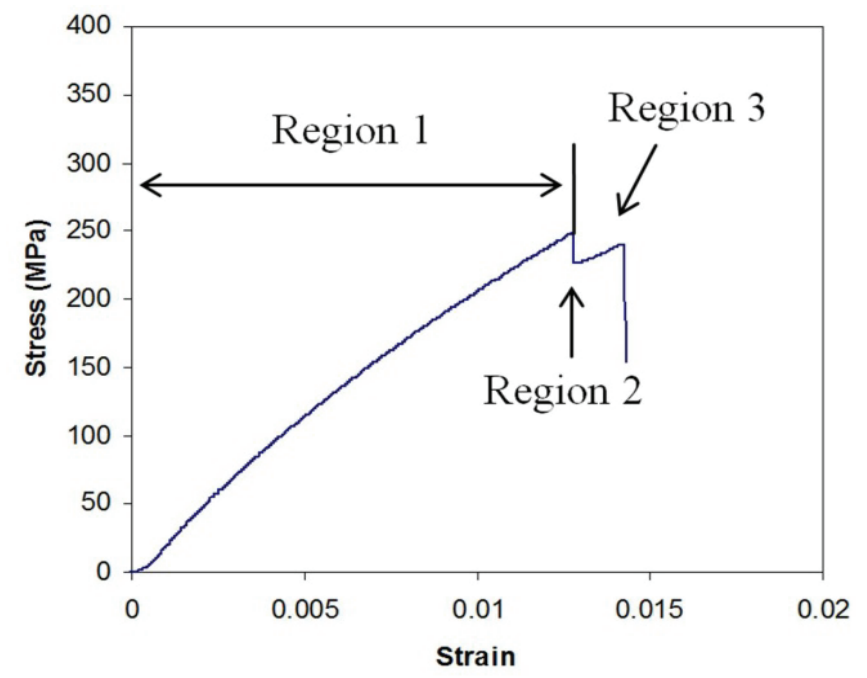

(a) A typical stress vs. strain graph (HYB-18 Specimen \#5-C) of the hybrid samples.

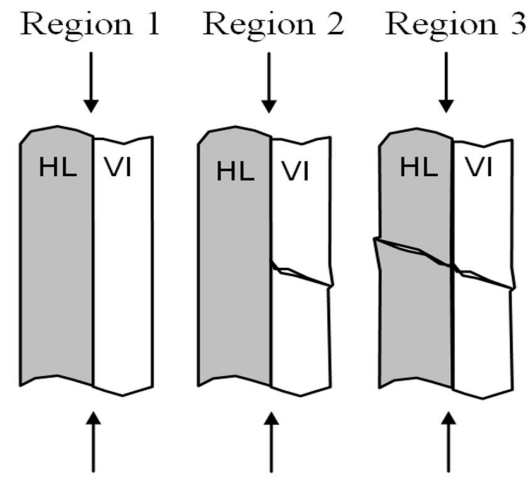

Compression loading direction

(b) The schematics of failure.

Fig. 9 A typical stress vs. strain graph (HYB-18 Specimen \#5-C) of the hybrid samples and the schematics of failure.

Here the curve steadily rises as both the HL and VI sides hold loading in region 1 . The curve reaches its maximum stress state at region 2 where the VI portion of the composite fails abruptly. Even though the VI portion is failed, the HL portion still remains intact and continues to carry load. Region 3 indicates that the curve steadily rises until the ultimate failure in the HL portion. Note that over half of the samples did not show region 3, because the HL portion has less compressive strength than the VI portion. For these samples the series of failures in the VI and HL sides of the hybrid composites occur almost simultaneously. In other words, ultimate failure usually occurs once the VI side of the sample finally ruptures in the gage section. The dominant failure mode in compression was gage section rupture caused by fiber kinking at the center of the sample where forces were concentrated.

Table 6 shows the average compressive properties for the two sample types, to include: ultimate compressive strength, maximum percentage strain at failure, and compressive modulus in $G P a$. From the data it was found that the material properties of HYB-18 and HYB-19 were almost identical in compression. It is worth noting that the HYB-19 sample has a higher modulus in regions 1 and 3 due to more HL plies and higher fiber content by weight. The modulus of region 1 for both composite samples is also very close to that (24.04 GPa) of the VH-12 sample. This is due to an identical VI layup and a HL side which does not add a lot of compressive strength. Also the average UCS for the hybrid composite samples is between 263 and $265 \mathrm{MPa}$ which is approximately $20 \%$ less than VH-12, but remains improved by $11 \%$ over the HL- 6 sample examined earlier.

Table 6 Compressive Properties of HYB-8 and HYB-9.

\begin{tabular}{|c|c|c|c|}
\hline \multicolumn{2}{|l|}{ Sample name } & HYB-18 & HYB-19 \\
\hline \multicolumn{2}{|c|}{ Sample thickness $(\mathrm{mm})$} & 7.75 & 7.80 \\
\hline \multirow{2}{*}{$\begin{array}{l}\text { Material } \\
\text { contents }\end{array}$} & $\begin{array}{l}\text { Resin content } \\
\text { (weight \%) }\end{array}$ & 42.3 & 41.9 \\
\hline & $\begin{array}{l}\text { Fiber content } \\
\text { (weight } \% \text { ) }\end{array}$ & 57.7 & 58.1 \\
\hline \multirow{4}{*}{$\begin{array}{l}\text { Compression } \\
\text { test results }\end{array}$} & $\begin{array}{l}\text { Modulus in } \\
\text { region } 1(\mathrm{GPa})\end{array}$ & 23.62 & 25.37 \\
\hline & $\begin{array}{l}\text { Max strength in } \\
\text { region } 2(M P a)\end{array}$ & 266.25 & 263.31 \\
\hline & $\begin{array}{l}\text { Modulus in } \\
\text { region } 3(\mathrm{GPa})\end{array}$ & 12.1 & 12.8 \\
\hline & Max \% strain & 1.441 & 1.309 \\
\hline
\end{tabular}

Fig. 10 gives the overall pictures and SEM micrographs of the fracture surfaces of a HYB specimen in compression. The pictures clearly show the failure modes that occur in the composite. The failure progression in compression is the opposite of tension, since the VI side fails first due to increased stiffness and lower maximum strain percent. The VI side tends to fail due to fiber kinking or shear crippling, which is a localized band across the specimen in which fibers rotate by a large amount (Schultheisz and Waas, 1995). The HL side of the hybrid composites usually demonstrates failure shortly after the VI side. The failure on the HL side is mostly caused by brittle or shear banding matrix material (Mallick, 2007). This is a typical failure mode in chopped fiber mat and is seen in the SEM (HL side) picture in Fig. 10. Overall there were no major delaminations of the HL and VI 
sides of the hybrid composite. This demonstrates the effectiveness of the bond between the sections and leads to the conclusion that this is an acceptable construction method. It is important to investigate the beneficial effects of the hybrid composites containing the hand-layup processed exterior skin and the vacuum infusion processed interior skin on local shock loads. Further research is being conducted on the impact response of the hybrid laminates.

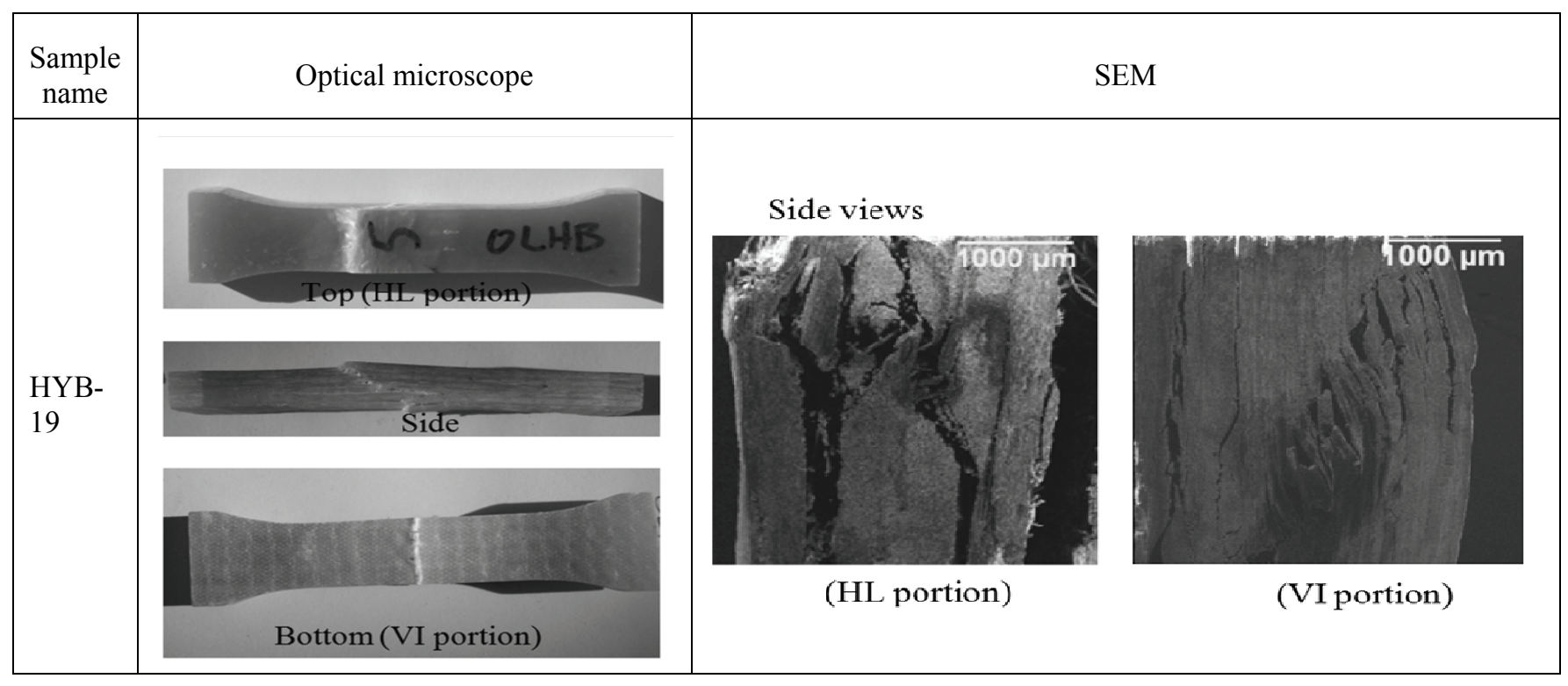

Fig. 10 Fractography of hybrid composite laminate after compression test (HYB-19 Specimen \#5-C).

\section{CONCLUSION}

In order to understand the effect of fabrication processes on the mechanical properties of marine composites, experimental studies were carried out on GFRP specimens. Three fabrication processes were used: HL, VI, and a combination of both called a hybrid (HYB). Following are the summaries of this investigation.

- In tensile testing, increases in vacuum pressure tend to increase the tensile properties of GFRP composites. HL samples contain many more vacancies than VI samples and tend to initiate failure through matrix cracking. VI however has far fewer vacancies and the dominant failure here is fiber extraction which gives the VI samples much more strength and stiffness.

- The compressive strength of the three systems tested was also heavily influenced by the layup technique. Modulus values increase as vacuum pressure increases just as in tensile samples. The trend of UCS on three samples with 6 plies was a little deceiving. Due to their thin cross sections, failure modes were generally end brushing for the 6 ply samples used which causes premature failure instead of normal gage section failure. Testing of a thicker sample with 12 plies led to far better results.

- Hybrid composites were found to display many of the characteristics from the HL and VI from which they are made. In tension the hybrid composites demonstrate failure in the HL side first, and in compression failure initiates in the VI side. In either case the UTS and UCS are comparable, but not quite as good as the vacuum infusion processed sample which these closely resemble. Delamination between both HL and VI sides was minimal and this indicates good adherence between two systems.

\section{REFERENCES}

ABS, 2000. Guide for building and classing motor pleasure yachts, Chapter 8 "design pressures", Chapter 9 "hull scantling, high speed craft. Houston, TX, USA: American Bureau of Shipping.

Adams, D. and Lewis, E., 1990. Influence of specimen gage length and loading method on the axial compressive strength of a unidirectional composite material. Experimental Mechanics, 31(1), pp. 14-21.

ASTM D2584: Standard test method for ignition loss of cured reinforced resins. ASTM Internatinal, West Conshohocken, PA, USA.

ASTM D3039: Standard test method for tensile properties of polymer matrix composite materials. ASTM Internatinal, West Conshohocken, PA, USA.

ASTM D695: Standard test method for compressive properties of rigid plastics. ASTM Internatinal, West Conshohocken, PA, USA.

Baley, C. Perrot, Y. Davis, P. Bourmaud, A. and Grohens, Y., 2006. Mechanical properties of composites based 
on low styrene emission polyester resins for marine applications. Applied Composite Materials, 13, pp. 1-22.

Belingardi, G. Cavatorta, M. and Paolino, D., 2008. repeated impact response of hand lay-up and vacuum infusion thick glass reinforced laminates. International Journal of Impact Engineering, 35, pp.609-619.

Belingardi, G. Cavatorta, M. P. and Paolino, D. S., 2008. Repeated impact response of hand lay-up and vacuum infusion thick glass reinforced laminates. International Journal of Impact Engineering, 35, pp.609-619.

Borsellino, C. Calabrese, L. and Bella, G., 2007. Effect of bonder at skin/core interface on the mechanical performances of sandwich structures used in marine industry. Applied Composite Materials, 14, pp.307-323.

Capello, F. and Manusco, A., 2001. Lay-up optimization for the hull of a racing sailing yacht. Advances in Engineering Software, 32, pp. 133-139.

Costa, M. L. Frascino, S. and Almeida, M. de, 2001. The influence of porosity on the interlaminar shear strength of carbon/epoxy and carbon/bismaleimide fabric laminates. Composites Science and Technology, 61(14), pp.2101-2108.

Fu, S.-Y. Lauke, B. Mäder, E. Yue, C.-Y. and Hu, X., 2000. Tensile properties of short-glass-fiber- and short-carbonfiber-reinforced polypropylene composites, composites Part A: Applied Science and Manufacturing, 31(10), pp.1117-1125.

Horsmon, A., 2001. Lightweight composites for heavy-duty solutions. Marine Technology, 38 (2), pp.112-115.
Mallick, P.K., 2007. Fiber reinforce composites: materials, manufacturing, and design. 3rd Edition, London, Great Britain: CRC Press, Taylor and Francis Group.

Modi, D. Correia, N. Johnson, M. Long, A. Rudd, C. and Robitaille, F., 2007. Active control of the vacuum infusion process. composites Part A: Applied Science and Manufacturing, 38(5), pp.1271-1287.

Mouring, S., 1999. Buckling and postbuckling of composite ship panels stiffened with preform frames. Ocean Engineering, 26, pp.793-803.

Mouritz, A. Gellert, E. Burchill, P. and Challis, K., 2001. Review of advanced composite structures for naval ships and submarines. Composite Structures, 53(1), pp. 21-4.

Rodriguez, E. Petrucci, R. Puglia, D. Kenny, J. and Vazquez, A., 2005. Characterization of composites based on natural and glass fibers obtained by vacuum infusion. Journal of Composite Materials, 39(3), pp. 265-282.

Schultheisz, C.R. and Waas, A.M., 1996. Compressive failure of composites, Part 1: testing and micro-mechanical theories. Progress in Aerospace Sciences, 32(1), pp.1-42.

Squires, C. Netting, K. and Chambers, A., 2007. Understanding the factors affecting compressive testing of unidirectional carbon fiber composites. Composites Part B: Engineering, 38(4), pp.481-487.

Thomason, J.L., 1995. The Interface region in glass fiber reinforced epoxy resin composites: 1. Sample preparation, void content and interfacial strength. Composites, 26, pp.467-47. 